\title{
NUMERICAL MODELING OF THE PROCESS OF DETECTION OF KARST CAVITIES IN RAILWAY EMBANKMENTS BY A GRID- CHARACTERISTIC METHOD
}

\author{
${ }^{1}$ Vladimir S. Egiyan, ${ }^{1,2}$ Alena V. Favorskaya, ${ }^{1}$ Aram A. Mkrtchyan, ${ }^{1,2}$ Igor B. Petrov, \\ ${ }^{1,2}$ Nikolay I. Khokhlov, ${ }^{1,2}$ Vasiliy I. Golubev \\ ${ }^{1}$ Moscow Institute of Physics and Technology, http://mipt.ru \\ Dolgoprudny, Moscow region 141700, Russian Federation \\ ${ }^{2}$ Scientific Research Institute of System Development of RAS, https://www.niisi.ru \\ Moscow 117218, Russian Federation
}

vladimir.yeghiyan@phystech.edu, aleanera@yandex.ru, aramaram94@mail.ru, petrov@mipt.ru, k_h@ inbox.ru,w.golubev@mail.ru

Abstract. Over the past 160 years, railways are one of the main elements of the top track structure throughout the world. They serve to direct the wheels when they move and directly perceive and transmit pressure to the underlying elements. Despite all the efforts of engineers, karst cavities can form under the rails due to severe operating conditions. One of the priority tasks is the development of methods for their detection in railway embankments by solving a series of direct problems. The purpose of this paper is to study the propagation of elastic waves in a railway embankment. We used a grid-characteristic method on curvilinear structural grids, which makes it possible to efficiently solve the tasks of monitoring the state of the railway embankment and paths, including taking into account the large number of integrity violations, to take into account the dynamic interactions in the system of rolling stock - the path, to obtain a complete wave pattern. A comparative analysis of calculations of a series of calculations with a variable geometry of the computational domain was carried out. Comparison of the propagation processes of elastic waves in the presence and absence of karst inclusions in the soil under the embankment is made, comparison of signals diagnosed in these cases from rails is given.

Keywords: computer simulation, grid-characteristic method, structural hexahedral grids, railway transport safety, karst cavities

UDC 519.63

Bibliography - 10 references

Received 14.11.2017

RENSIT, 2017, 9(2):215-220

DOI: 10.17725/rensit.2017.09.215

\section{CONTENTS}

1. INTRODUCTION (215)

2. Model and Method (216)

3. Results and Discussion (217)

4. Conclusion (219)

REFERENCES (219)

\section{INTRODUCTION}

To solve the real problems of monitoring of the state of rolling stock and tracks it is necessary to take into account the dynamic interactions in the system of the rolling stock - the path, to study the spatial dynamic wave pattern, to take into account the characteristic properties of the dynamic system of equations of deformable solid body [1]. Currently used methods are approximate and do not allow us to reproduce the complete wave picture of the processes occurring in the structure under consideration. While the study of these processes will make it possible to make diagnostics of the rolling stock and ways more efficient.

Since the system of equations for the mathematical model of the state of a continuous linearly elastic medium [2] is 
hyperbolic and a high-precision calculation of wave processes is required, it is optimal to use the grid-characteristic method [3-7].

\section{MODEL AND METHOD}

In this work the system of linear elasticity is used [2]

$$
\begin{aligned}
& \rho \partial_{t} \vec{v}=(\nabla \cdot \boldsymbol{\sigma})^{\mathrm{T}}, \\
& \partial_{t} \boldsymbol{\sigma}=\lambda(\nabla \cdot \vec{v}) \mathbf{I}+\mu\left(\nabla \otimes \vec{v}+(\nabla \otimes \vec{v})^{\mathrm{T}}\right) .
\end{aligned}
$$

Equation (1) is the local motion equation. Here $\varrho$ - material density, $\vec{v}$ - velocity, $\sigma-$ stress tensor. Equation (2) is related to the Hook's. Here $\lambda, \mu$ - Lame parameters.

For numerical solution of system (1), (2) the grid-characteristic method on curvilinear structured meshes was used that allows to build correct numerical algorithms for calculating boundary points and points lying on the interfaces of two media with different Lame parameters and (or) densities. In $2 D$ case it can be written as

$$
\partial_{t} \vec{q}+\mathbf{A}_{1} \partial_{x_{1}} \vec{q}+\mathbf{A}_{2} \partial_{x_{2}} \vec{q}=0 .
$$

In equation (3) $\vec{q}$ denotes vector from 2 components of velocity and 3 components of stress tensor

$$
\vec{q} \in\left\{v_{1}, v_{2}, \sigma_{11}, \sigma_{22}, \sigma_{12}\right\}^{\mathrm{T}} \text {. }
$$

Initially we split our system be directions into 2 independent systems:

$$
\frac{\partial \vec{q}}{\partial t}=\mathbf{A}_{j} \frac{\partial \vec{q}}{\partial x_{j}} .
$$

Both of them are hyperbolic and can be written as:

$$
\frac{\partial \vec{q}}{\partial t}=\boldsymbol{\Omega}_{j}^{-1} \boldsymbol{\Lambda}_{j} \boldsymbol{\Omega}_{j} \frac{\partial \vec{q}}{\partial x_{j}},
$$

$\boldsymbol{\Omega}_{\mathrm{j}}$ - matrix from Eigen vectors, $\boldsymbol{\Lambda}_{\mathrm{j}}-$ diagonal matrix from Eigen values. For all directions $\boldsymbol{\Lambda}$ can be written as (don't use index $j$ further):

$$
\mathbf{\Lambda}=\operatorname{diag}\left\{c_{p},-c_{p}, c_{s},-c_{s}, 0\right\},
$$

where $c_{p}=\sqrt{(\lambda+2 \mu) / \rho}-P$-wave velocity, $c_{s}=\sqrt{\mu / \rho}-S$-wave velocity.

Using $\quad \vec{q}=\boldsymbol{\Omega} \vec{p} \quad$ both systems (4) splits into independent transport equations:

$$
\frac{\partial \vec{q}}{\partial t}+\Lambda \frac{\partial \vec{q}}{\partial x}=0
$$

Each $1 D$ equations are solved with gridcharacteristic or finite-different schemes.

Finally, the solution can be obtained by

$$
\vec{q}^{n+1}=\mathbf{\Omega}^{-1} \vec{p}^{n+1} \text {. }
$$

At the Moscow Institute of Physics and Technology under the supervision of Corresponding Member of the Russian Academy of Sciences Igor B. Petrov a research software was developed that uses the described method. The program implements the use of TVD-difference schemes of the second order of accuracy [8], 15 different limiters. In the calculations, the superbee limiter [9] and grid-characteristic schemes of the 2-4 order of accuracy are mainly used [10]. Fig. 1 shows a graph of the acceleration of the software when using MPI technology, which indicates a high degree of its parallelization.

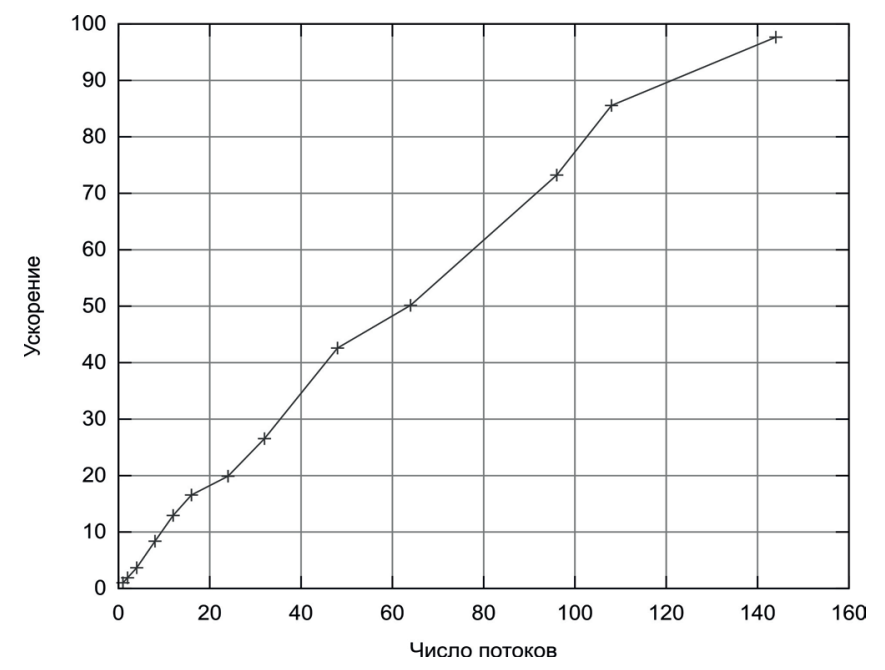

Fig. 1. Computation speedup with MPI and mesh with 64 million nodes. 


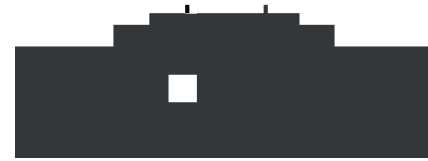

$a$

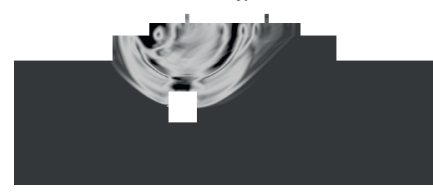

$c$
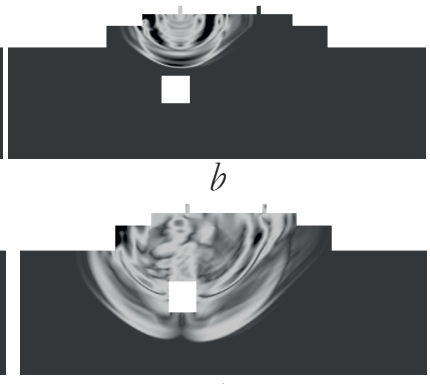

$d$

Fig. 2. Wave processes in embankment. a) Initial perturbation, b) Perturbation propagation, c) First seismic response creation, d) Second seismic response creation.

\section{RESULTS AND DISCUSSION}

Fig. 2 shows the propagation of elastic waves in an embankment with a karst inclusion. Fig. 2a shows the initial perturbation. Fig. $2 \mathrm{~b}$ shows the further propagation of elastic waves in the rails, embankment and ground. Fig. $2 c$ shows the creation of the first response from the karst inclusion, and Fig. $2 \mathrm{~d}-$ the second response. In Fig. $2 \mathrm{a}-2 \mathrm{~d}$ gradation of gray shows the velocity modulus. The calculations were carried out by a gridcharacteristic method on a grid consisting of 200,000 nodes, the boundaries of the integration region are free, karst inclusion is

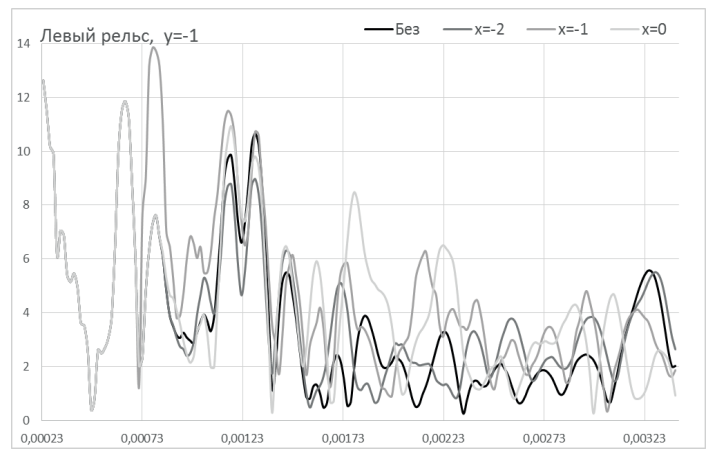

Fig. 4. Functions $v(t)$, cavern size $-(0.5 \times 0.5)$, depth $-y=-1$.

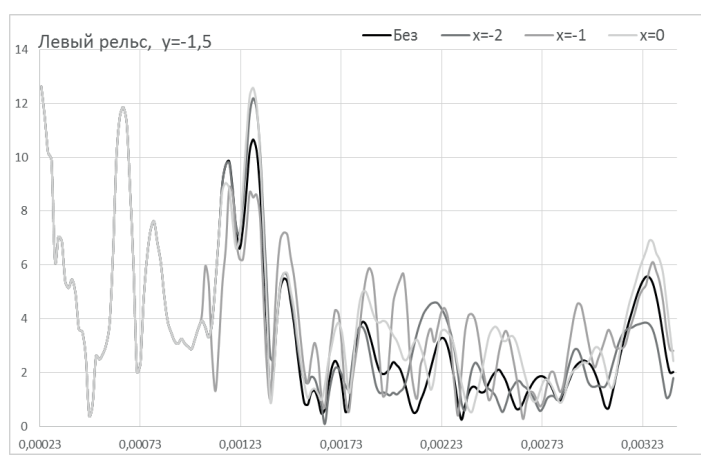

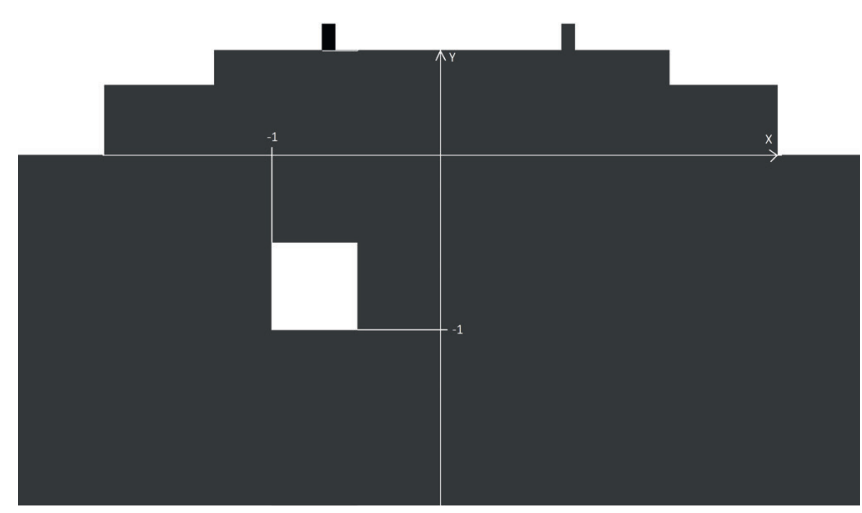

Fig. 3. Embankment with coordinate lines that determine the location of the karst cavities.

also given by a free boundary, the condition of complete adhesion is used at the contact boundaries between the railway embankment and rails.

Figures 4-8 show the dependencies (seismic traces) obtained from the left and right rails for different sizes and locations of the cavities. On all graphs, the black line corresponds to the calculation without karst inclusion, and the gray scale line - with karst inclusions at different places. Fig. 3 shows an embankment with coordinate lines.
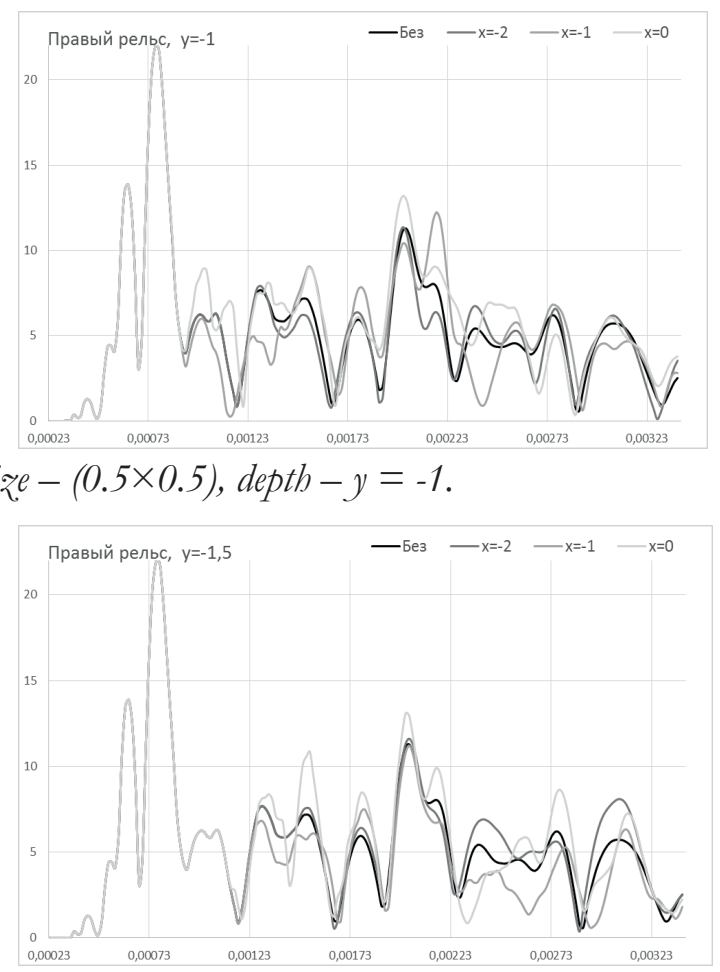

Fig. 5. Functions $v(t)$, cavern size $-(0.5 \times 0.5)$, depth $-y=-1.5$. 

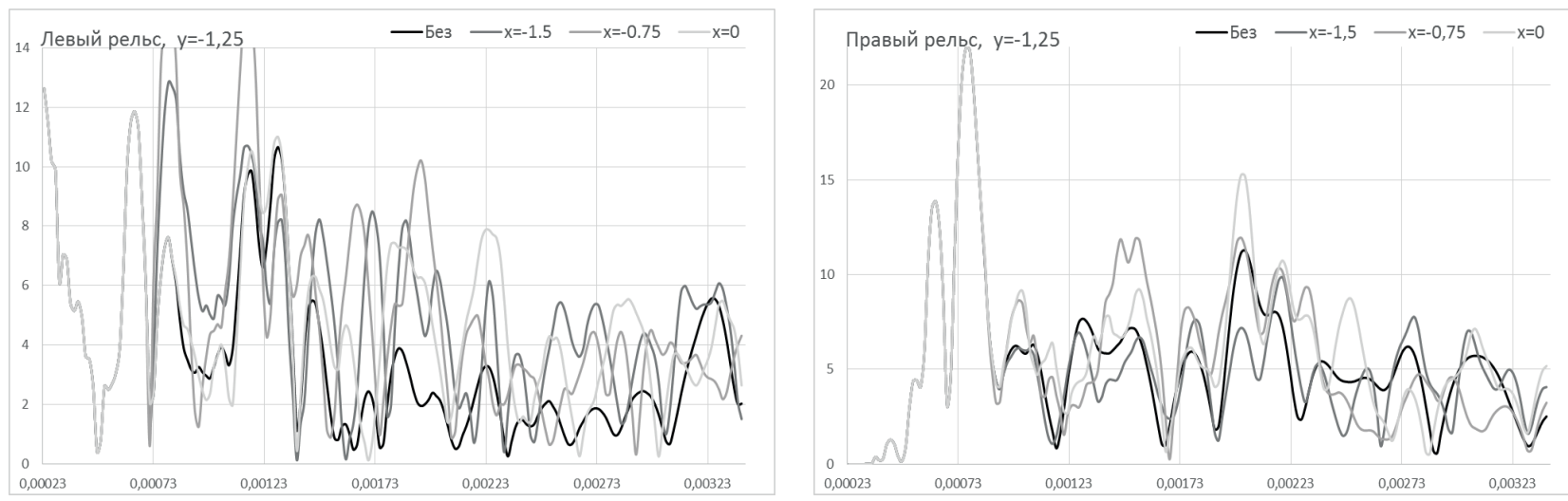

Fig. 6. Functions $v(t)$, cavern size $-(0.75 \times 0.75)$, depth $-y=-1.25$.
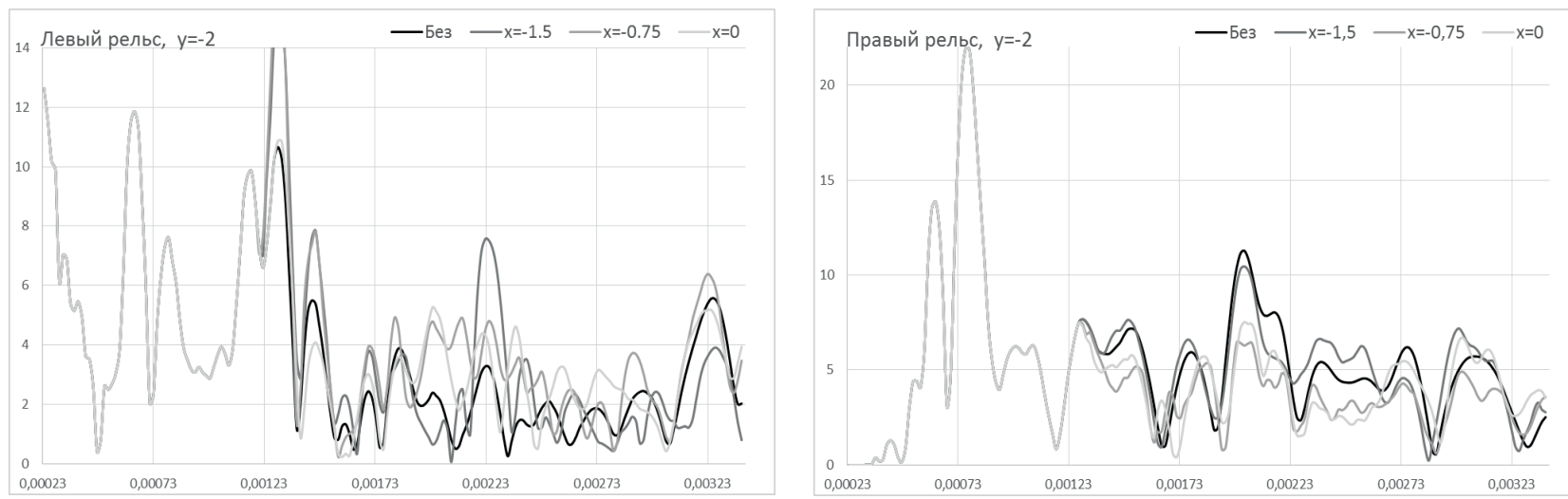

Fig. 7. Functions $v(t)$, cavern size $-(0.75 \times 0.75)$, depth $-y=-2$.
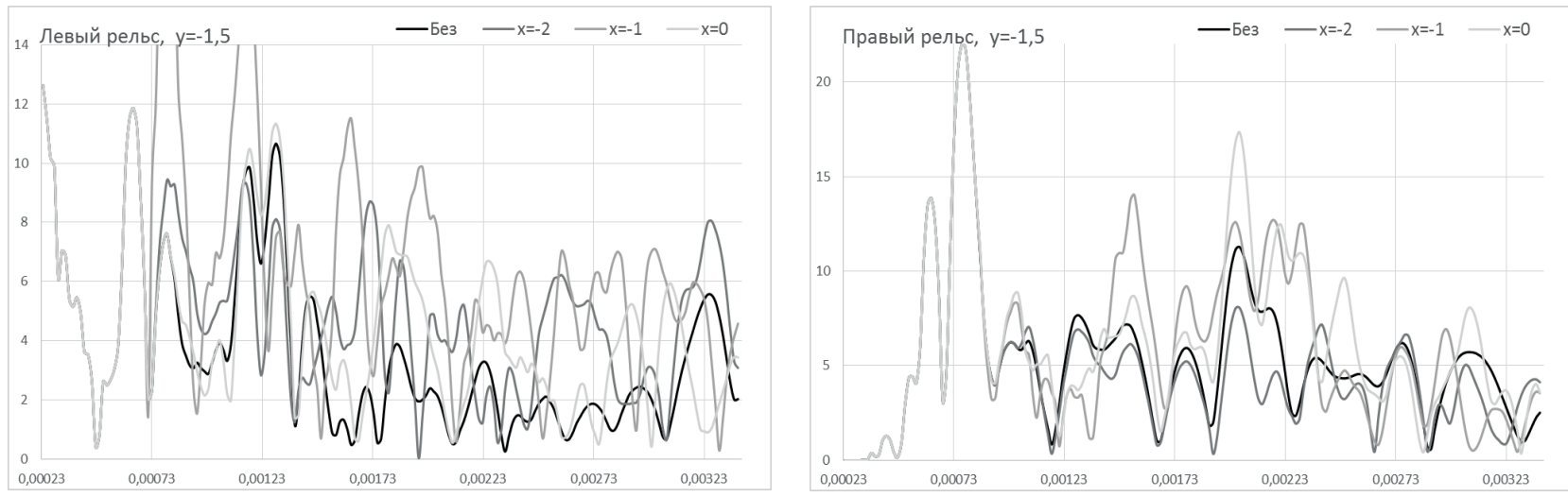

Fig. 8. Functions $v(t)$, cavern size $-(1.0 \times 1.0)$, depth $-y=-1.5$.

Fig. 4-8 depict dependencies obtained At the beginning all the lines on the graphs are from the left and right rails for three different sizes of the cavity. Fig. 4-5: cavern size $0.5 \times 0.5$, Fig. 6-7: cavern size $0.75 \times 0.75$ and Fig. 8: cavern size $1.0 \times 1.0$. On each graph, it is written from which rail the data were measured and the location of the karst cavity (see Fig. 3).

Fig. 4 shows plots in the case of a cavern with a size of $0.5 \times 0.5$ and a depth of $y=-1$. coincide. This means that the wave reflected from the cavern did not reach the rail, and at some point in time the discrepancy between the measurement results with the cavern (lines with gray gradation) and without (black line) is already visible. Comparing the data obtained from the left and right rails, we see that on the left rail the discrepancy begins 
earlier than on the right, since the initial disturbance was placed on the left rail.

Similar conclusions can be drawn for Fig. 5-8. Comparing the data with the different sizes of the cavern, we see that in the case of large caverns, the lines diverge more than in the case of small caverns, since the reflection line of the wave is longer and therefore the waves are more reflected. Let's compare the data of caverns with different depths under the ground. And we will see that the deeper the cavern lies, the weaker the reflected wave and therefore it is impossible to detect deep caverns. But in this case, there is less likelihood that the cavern will interfere with the movement of the train. And so it is not necessary to detect deep-lying caverns.

Based on the results of measurements, it can be argued that in all cases it is more accurate to locate and determine the location and size of the cavity under the left rail than under the right (initial disturbance of the wave was placed on the left rail).

\section{CONCLUSION}

In this article we present developed methods for the detection of karst cavities on railway embankments by solving a number of direct problems. A comparative analysis of the calculations obtained by the gridcharacteristic method was carried out. Comparison of the propagation of elastic waves in the presence and absence of karst inclusions in the soil under the embankment is made, a comparison of the signals registered in these cases at rails is given. Comparing the results, we see that this method can accurately determine the location and size of the cavity. The further direction of the work is the solution of the inverse problem by the comparison of calculated and experimental data.
The reported study was funded by RFBR and JSC Russian Railways according to the research project № 17-20-01096.

\section{REFERENCES}

1. Cannon DF, Edel KO, Grassie SL, Sawley K. Rail defects: an overview. Fatigue \& Fracture of Engineering Materials \& Structures, 2003, 26(10):865-886.

2. Novatskii VK. Teoriya uprugosti [Elastic Theory]. Moscow, Mir Publ., 1975, 872 p.

3. Petrov IB, Kholodov AS. Numerical study of some dynamic problems of the mechanics of a deformable rigid body by the mesh-characteristic method. Zhurnal vychislitel'noy matematiki $i$ matematicheskoy firiki [Computational Mathematics and Mathematical Physics], 1984, 24(3):61-73 (in Russ.).

4. Golubev VI, Gilyazutdinov RI, Petrov IB, Khokhlov NI, Vasyukov AV. Simulation of dynamic processes in three-dimensional layered fractured media with the use of the grid-characteristic numerical method. Journal of Applied Mechanics and Technical Physics, 2017, 58(3):539-545.

5. Kvasov IE, Pankratov SA, Petrov IB. Numerical simulation of seismic responses in multilayer geologic media by the grid-characteristic method. Matematicheskoe modelirovanie [Math Models Comput Simul], 2011, 3(2):196-204 (in Russ.).

6. Petrov IB, Favorskaya AV, Sannikov AV, Kvasov IE. Grid-characteristic method using high-order interpolation on tetrahedral hierarchical meshes with a multiple time step. Matematicheskoe modelirovanie, 2013, 5(5):409-415 (in Russ.).

7. Muratov MV, Petrov IB. Estimation of wave responses from subvertical macrofracture systems using a grid 
characteristic method. Matematicheskoe modelirovanie, 2013, 5(5):479-491 (in Russ.).

8. Harten A. High resolution schemes for hyperbolic conservation laws. Journal of ComputationalPhysics, 1997, 135(2):260-278.

9. Roe PL. Characteristic-Based Schemes for the Euler Equations. Annual Review of Fluid Mechanics, 1986, 18:337-365.

10. Kholodov AS, Kholodov YA. Monotonicity criteria for difference schemes designed for hyperbolic equations. Zhurnal yychislitel'noy matematiki i matematicheskoy firiki, 2006, 46(9):15601588 (in Russ.). 